\title{
Analysis of Huawei's Global Supply Chain
}

\author{
Yongjun $\mathrm{Ni}$ \\ Department of Economic Management, North China Electric Power University, Baoding 071003, \\ China.
}

1538322596@qq.com

Keywords: Huawei; supply chain; factor endowment theory; product life cycle theory.

\begin{abstract}
With the pace of economic and trade globalization, more and more companies have carried out business around the world, and continuously innovate their own supply chain to maximize their benefits. "Huawei", as a leader, has taken the lead in the world in the process of building a global supply chain. This paper analyzes the collaborative management effect of Huawei's supply chain from both internal and external parts. It also uses the factor endowment theory and product life cycle theory as the support of the theory. According to Huawei's supply chain construction process, it provides suggestions for other multinational companies.
\end{abstract}

\section{Company Background}

Huawei Technologies Co., Ltd. is a private communications technology company that produces and sells communications equipment. It was formally incorporated in 1987 and is headquartered at Huawei Base Station, Bantian, Longgang, Shenzhen.

Huawei is the world's leading information and communication technology (ICT) solutions provider, focusing on the field of ICT. Huawei implements the strategy of global operation. As of the end of 2016, Huawei has branches or representative offices in 168 countries around the world. At the same time, 16 research institutes, 28 innovation centers and 45 product service centers have been established in the United States, Europe, Japan, India, Singapore and other regions according to the capabilities of different countries and regions. Huawei has the world's largest R \& D team of more than 70,000 people, investing $10 \%$ of its annual sales revenue in research and development and accumulatively obtaining 36,511 patents. In the past 10 years, Huawei has invested a total of 25 billion U.S. dollars in R \& D. (Chen Bingbing,2004)

In such a global market network and R \& D platform, R \& D needs of products from Huawei, the framework designed by top European and American experts, the hardware is completed by the Huawei China team, the software is mainly undertaken by Indian scientists and technicians, manufactured mainly by Foxconn, and finally sales in Huawei's global market network.

In 2015, Huawei supported the stable operation of more than 1,500 customer networks and ensured the stability of more than 130 major event / natural disaster networks in the world.

\section{Supply Chain Analysis}

\subsection{Collaborative Management of Internal Supply Chain.}

Since 1994, Huawei has applied MRP system for enterprise resource allocation and started using MRP II in 1997. Since 2000, the construction of Integrated Supply Chain (ISC) has been underway. (Zhang Jingmin,2004) The continuous upgrading of the internal operation for the supply chain has underpinned the rapid growth of Huawei. Meanwhile, based on the efficient planning and operation system, each product according to market demand and inventory situation, held S \& OP (sales operations planning) meeting, according to floatings in market demand, continue to keep supply and inventory in balance. Through overall planning and macro-control system to ensure collaborative supply chain services.

In 2002, to support the efficient and low-cost development of the fast-growing production activities and to improve the efficiency and accuracy of the management of warehouse operations and material handling, Siemens Dematic was commissioned to build a world-class, high-bay 
warehouse with 20,000 trays and over 40,000 bins near the production center and an automated warehouse with 13 pallet transfer stackers and 7 magazine conveyor stackers.

Starting in 2005, Huawei consulted with i2 to build a global supply chain (GSC). Upgrading the functions and functions of the supply chain already covered in Asia Pacific, Europe, Latin America, North Africa, Middle East, North America, and Russia, South Africa and other places, the delivery capacity of the last mile close to the customer is improved.(Yang Xiaokai and Zhang Yongsheng,2001) The deployment of global resources are also supported in the chain of supply by advanced IT systems such as ERP (Enterprise Resource Planning) and ASP (Advanced Planning Scheduling), and mobilizes the best fulfillment conditions in the world to meet customer needs.

\subsection{External Supply Chain Collaborative Management.}

Huawei has established a very good partnership with suppliers and carriers and implemented hierarchical and hierarchical management of suppliers. In terms of supplier management, we have established detailed certification standards and systems to strictly certify suppliers through seven aspects: quality, technology, response, cost, delivery, social responsibility and environmental protection. Through SCC (Supply Chain Collaboration) system, the real-time interaction between demand and supply of suppliers was built to guarantee the supply stability and timeliness.

And since Huawei joined Rosetta Net in 2004, B2B trading has been facilitated with strategic suppliers, greatly simplifying the procurement process and improving the accuracy of information. (Hill Charles,2007) Through continuous running-in and exchange, we have formed a win-win relationship with our partners. Huawei constantly advances itself and partners with suppliers. Huawei's global supply chain has passed the local LSP authentication. Find out about the delivery of local customs clearance and other support services that are closest to customers. Nearly 500 shipping lines cover the world and strategic partnerships with advanced logistics partners enable Huawei to accurately receive Huawei products in every corner of the world.

Services such as economical rework, original rework, pre-rework and accelerated rework are available to customers from 128 backup centers around the world, with a 2- to 4-hour, NBD (Next Business Day) replacement for critical components. (Kenneth L. Sokoloff, Stanley L. Engerman, 2000) Huawei is always on the side with customers, willing to provide professional, high-quality service to them. Additionally, Huawei establishes a management process of risk within its supply chain. Each execution step is controlled according to risk management analysis, identification, processing and evaluation. In particular, the establishment of a system of production continuity to identify and prevent crisis points that may affect the production continuity and to formulate exercise plans based on emergency measures so as to ensure the continuity of supply can be fully guaranteed.

\subsection{Huawei's Supply Chain Collaborative Management Effect.}

According to IBM consultants, Huawei has a large gap in management level with other companies in the industry before restructuring its supply chain. Huawei's order delivery rate was only $50 \%$ on time, compared with $94 \%$ for other telecom equipment manufacturers in the world. As for the rate of inventory turnover, Huawei gets 3.6 times / year, while the international average of 9.4 times / year. After the supply chain restructuring, Huawei's timely arrival rate increased little by little, nearly $40 \%$ higher than in 2001, rate of inventory turnover increased by nearly 1 times.

Before the new automated warehouse was built, almost half of Huawei's 60,000-square-meter production center (26,000 square feet) was used for storing goods. Siemens Dematic positioned its warehouses outside, enabling Huawei to emancipate the previously occupied space in the production center to meet requirements of new production. The new warehouse still stores the same quantities of goods, but only 13,000 square meters of space, equivalent to saving half of the storage space. At the same time, the total costs of the warehouse are still the same as before.

More operating costs will be saved for Huawei in the future. Due to collaborative supply chain management, inventory and order accuracy increased from $96 \%$ to $99.5 \%$. The manual system used in the past had a problem of 2 days lagging behind in the flow of information. When the new goods entered, it took a full two days for the delivery of the goods details to the ERP system. Today, through the use of wireless data communications, the new goods will be able to use the time in less than a day. 
In addition, within the supply chain, the individual needs of the customer will be used to provide supply production and solutions, with the maximum synergy to meet the most customer needs. By the IT system recording and customizing customer needs, to ensure that all aspects of order fulfillment can accurately receive the customer's special needs information, to achieve the perfect delivery of the contract end-to-end.

\section{Theoretical Analysis}

\subsection{Factor Endowment Theory.}

In 1919, the basic idea of factor endowment theory was put forward by the Swedish economist Eil F Heckscher, pointing out two conditions necessary to create a comparative advantage difference.

In the 1930s, this argument was substantiated by his student Beltil G Ohlin, whose masterpiece "Interregional trade and international trade" further developed the theory of factors of production endowment, and this theory is also called HO theory. (Marrewijk, Charles,2007)

Its core content is as follows: There are two reasons for the comparative cost difference under the premise of equal technological level between the two countries: First, the elemental abundance of the two countries is different; second, the factor concentration of the commodity production is different.

According to the theory of factor endowment, a country's comparative advantage product is a product that should be exported. It is a product that it needs to intensively use the relatively abundant and cheap factor of production in the country for its production. Imported products, on the other hand, are products that it needs to produce intensively using the relatively scarce and expensive production factors in the country.

Countries should make full use of the abundant elements of their own country to produce them for export as products and export them in exchange for those products that use their scarce elements intensively. Such trade patterns have improved the well-being of participating countries.

\subsection{Product Life Cycle Theory.}

Raymond Vernon combines the theory of product life cycle in marketing with technological advances to illustrate the formation and development of international trade. in 1966, he pointed out that the direct investment of American enterprises is closely related to the product life cycle.

The theory of country transfer in the production of this product assumes that the transmission of information between countries is subject to certain restrictions, that the production function is variable and that the consumption structure in each country is different.(Bardhan, Ashok Deo, and Jaffee, Dwight,2004) It is pointed out that the products have different requirements on factors of production at different stages of their life cycles, and the richness of the factors of production in different countries determines the stage of production and the export of the country.

\section{Summary}

The difference in factor endowments around the world, coupled with the different life cycles of the products, also have different demands on the factors. Therefore, multinational corporations can make use of the resources in their hands and fully mobilize the elements around the world to minimize the costs.

During the entire life cycle of a product from entering the market and finally exiting the market, the enterprise or entrepreneur sets different strategic goals for each stage of their product. Attracting customers is the main purpose of the introduction period. Occupying the market is the main goal of the growth period. In maturity, it is to build a corporate brand, while developing new products is a strategic purpose during the recession. As for the sales, under the guidance of this goal, enterprises can rationally arrange the manpower and financial resources of enterprises and form effective marketing strategies to create profits.

We know that in the HI-based marketing approach, the change of channels restricts the choice of the logistics needs of enterprises, so the change of marketing methods will change the logistics needs of enterprises. In addition, from a supply point of view, the strategic goals of different life cycle stages of a product can have a dramatic impact on supplier selection, business purchasing decisions, 
inventory management, and more. In other words, from the perspective of the entire product supply chain, different strategic objectives of different life cycles of products require different supply chain strategies to match them, and enterprises should choose their own logistics operation mode dynamically from this point of view.

The allocation of resources throughout the international trade process is fragmented. Although enterprises can reduce their costs through economies of scale, labor costs and specialization and realize higher profits than domestic production, their profits do not come from the best allocation of resources. First of all, the costs incurred by the parties involved in the supply chain of information, logistics and warehousing are significant. The cost of international trade in the supply chain in developing and underdeveloped countries is even greater. Second, due to the poor correlation between enterprises in the supply chain, they are not cooperative and mutually beneficial relations, but a squeezed relationship. Therefore, enterprises with high production efficiency do not help related enterprises to improve their production efficiency and management level.

Therefore, there is still a lot of waste in resource allocation in the backward countries. For instance, the turnover rate of current assets of Chinese enterprises is only 1.62 times / year, while that of US and German companies is 8 times / year. The turnover rate of Japanese enterprises' current assets is 7 times / year or above. In developed countries, the ratio of total merchandise in stock value to GDP is only $1 \%$, while the ratio in China is as high as $37 \%$.

As all businesses are seeking greater benefits, global supply chains emerge. After the global supply chain is formed, the scale economy and the division of labor in international trade have been developed to a certain extent. As a result, costs and information barriers have been increased. However, through the application of the global supply chain system, consumers and producers are integrated, the utilization of resources is increased, and transaction costs are reduced. The core enterprises can concentrate the resources of their international trade-related enterprises on the realtime supply chain network information platform and make use of the smooth information to reduce inventory, logistics and capital waste to the lowest level. At the same time, due to resource sharing and long-term supply chain partnership, all the resources in international trade are coordinated by the core enterprises. Therefore, the overall resource utilization of the whole world can be improved.

\section{References}

[1]. Chen Bingbing: Supply Chain Management - Strategy, Technology and Practice [M]. Beijing: Electronic Industry Press .2004: 451

[2]. Zhang Jingmin: Chinese enterprises to implement supply chain management difficulties and countermeasures [J]. Integrated Transportation. 2004 (7)

[3]. Yang Xiaokai Zhang Yongsheng: new trade theory, comparative advantage theory and its empirical research new achievements: a literature review [J]. Economics Quarterly 2001 (10): 19-37

[4]. Hill, Charles (2007). International Business Competing in the Global Marketplace 6th ed. McGraw-Hill. p. 168. ISBN 978-0-07-310255-9.

[5]. Kenneth L. Sokoloff, Stanley L. Engerman (2000). "History Lessons: Institutions, Factor Endowments, and Paths of Development in the New World" (PDF). The Journal of Economic Perspectives. 14 (3): 217-232.

[6]. Marrewijk, Charles van (2007-01-18). "absolute advantage" (PDF). Department of Economics, Erasmus University Rotterdam:world economy. Princeton University Press. Retrieved 2009-0503.

[7]. Bradman, Ashok Doe, and Jaffee, Dwight (2004), "On Intra-Firm Trade and Multinationals: Foreign Outsourcing and Offshoring in Manufacturing" in Monty Graham and Robert Solow eds., the Role of Foreign Direct Investment and Multinational Corporations in Economic Development. 